\title{
Erratum to: BootES: An R package for bootstrap confidence intervals on effect sizes
}

\author{
Kris N. Kirby • Daniel Gerlanc
}

Published online: 30 August 2014

(C) Psychonomic Society, Inc. 2014

Erratum to: Behav Res

DOI 10.3758/s13428-013-0330-5

There is an error in Equation (9), Appendix 2: the term in parentheses in the numerator should be raised to the third power. We thank Tobias Johansson for bringing this omission to our attention.

The correct equation is: $a=\frac{\sum\left(\bar{\theta}-\widehat{\theta}_{-i}\right)^{3}}{{ }_{6}\left[\sum\left(\bar{\theta}-\widehat{\theta}_{-i}\right)^{2}\right]^{3 / 2}}$

Also, on p. 919, the citation "Rosnow et al., 2000, pp. 128130 " should have been "Rosenthal et al., 2000, pp. 128-130." The reference is to

Rosenthal, R., Rosnow, R. L., \& Rubin, D. B. (2000), Contrasts and effect sizes in behavioral research. NY: Cambridge University Press.

We thank Pierre Dragicevic for catching this error.

The online version of the original article can be found at http://dx.doi.org/ 10.3758/s13428-013-0330-5.

K. N. Kirby $(\bowtie)$

Department of Psychology, Williams College, Williamstown,

MA 01267, USA

e-mail: kkirby@hush.com

D. Gerlanc

Enplus Advisors Inc., Cambridge, MA, USA 